\title{
FREE RADICAL ANNULATION OF CYCLOPENTANE RING
}

$$
\text { Živorad Ćekovié* and Radomir Saičić }
$$

Department of Chemistry, Faculty of Sciences, University of Belgrade, Studentski trg 16, 11001 Belgrade, Yugoslavia

Abstract: Homoallyl radical, e.g. 2 , reacts bich an electron-deficient olefinic bond $\underline{I}$ with a new $C-C$ bond forming and arising of a 5-hexenyl radical 3 which further undergoes to j-exo-trigonal cyclization with a cyclopentane ring (느) annulation.

Regioselective intermolecular addition of an alkyl radicals onto the electron-deficient olefinic bond become an userul reaction for carbon-carbrn bond formation'. 'l'his general reaction is indepenendent of the radical precursors and of the Michael acceptors. On the other hand intramolecular cyclization of $5-h e x e n y l$ radical to the cyclopentylmethyl radical is well known reaction for the construction of carbocyclic ${ }^{2-7}$, and heterocyclic rings $8-10$. This reaction is stereoelectronically controlled and also proceeds regardless of the alkenyl radical precursors ${ }^{3}, 8$. Alkenyl radical cyclization has been systematically investigated and applied in the synthesis of variety cyclic and polycyclic organic molecules $6,7,9$ and natural $\operatorname{products}^{10-12}$.

We conceived to connect Giese's intermolecular radical conjugated addition (step A, Scheme 1.) and Walling-Beckwith's intramolecular 5-hexenyl radical cyclization (step B) into one sequence of radical chain reactions, in order to close a cyclopentane ring from two unsaturated molecules.

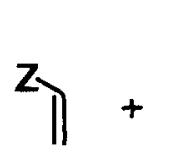

1

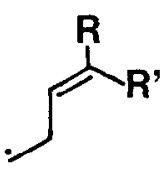

2

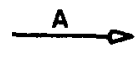

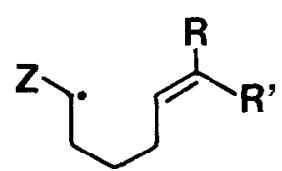

3

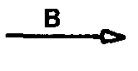

Scheme 1.

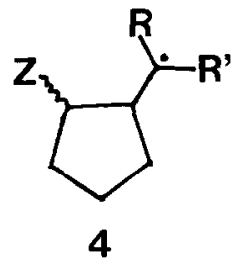

We found that annulation of cyclopentane ring can be achieved by tri-nbutyltin hydride reduction of homoallyl halides $\underline{5}$ ( $X=$ I or Br) in an excess of electron-deficient olefinic compounds 1 ( $\mathrm{Z}=\mathrm{CN}, \mathrm{CoOEt}, \mathrm{COCH}_{3}$, CHO) (Scheme 2 .).

Annulation of cyclopentane ring by addition of homoallyl radical 2 , as a three carbon block, onto the conjugated olefinic bond 1 , as a radicophilic two carbon block, represent a two $C-C$ bond forming reaction, i.e. 2 + 3 stepwise cycloaddition reaction. Cyclopentane ring annulation was observed in the $\beta$-acetylenic radical addition onto the conjugated olefinic bond ${ }^{13}$. 


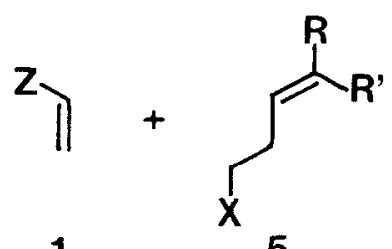

1

5

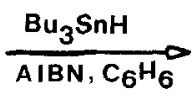

The oycjization poactons were generally performed by treating of homoall haltides 5 ( 1 I mole) with tri-n-butyltin hydride (12 mmole), ton times excess of acrylonitrile or othar electron-deficient nlefinic compounds (lPO mmole) and ATPN as an initiator in benzene or other solvent with refluxing in an inert atmosphere. products were isolated ${ }^{14}$ and separated by column (Siop) or sas cinomatography and characterjzed by ir, $H$ nmr and mass spectra (Table 1 ).

Table 1. Annulation of cyclopenlane ring. Producte and theiryields (\%)

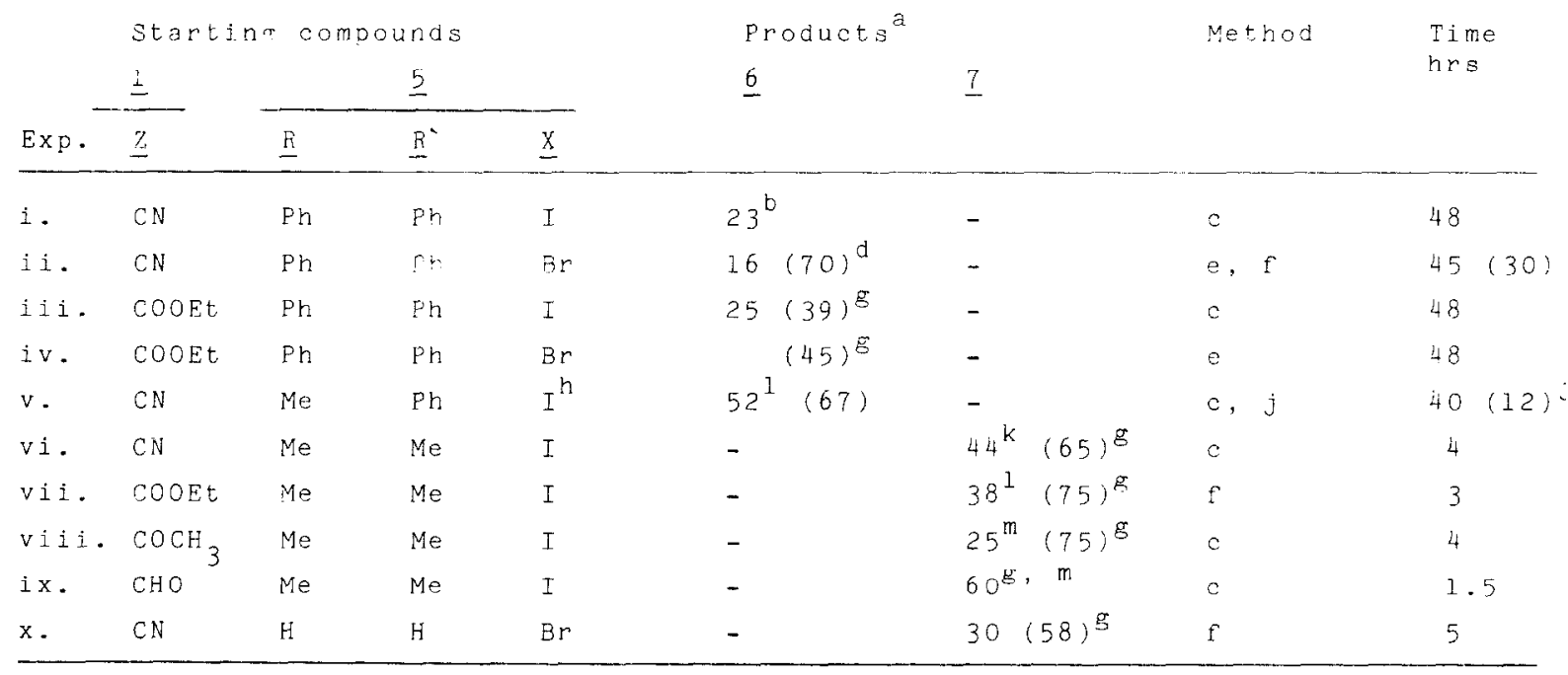

a. Isolated yields after column chromatograph.

b. Mixture of cis- and trans-isomers in ratio of $1: 2$.

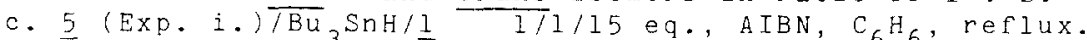

d. $\bar{Y}$ ield calculated on the converted bromide $5^{6}$ (Exp. i.).

e. Toluene was used as a solvent.

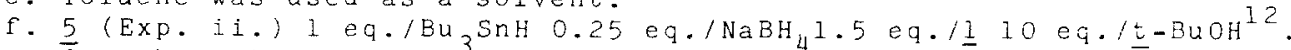

s. Gas chromatography yields.

h. Mixture of $Z$ and $E$ isomers was used.

i. Mixture conțaining trans-isomer and two cis-enantiomers was separated by gc, (lo\%

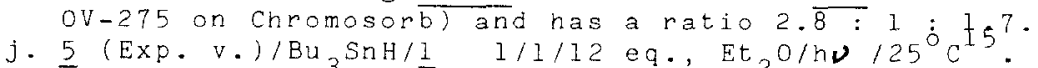

k. Mixture of two ${ }^{3}$ somers in ratio of 2 ? 1 .

1. Ratio of two isomers is 0.7 : 1 .

matio of isomers is 3 : 1 .

For example, reaction of 4-phenyl-3-penten-l-yl iodide 5 (Exp. v.) with tri-n-butyltin hydride and acrylonitrile, under above conditions, afforded as a majo product the mixture of cis- and trans-2-(1-phenylethyl)-cyclopentyl cynide 6 (52\%), together with the minor by product $\overline{2-p h e n y l-2-p e n t e n e ~ a n d ~ s t a r t i n g ~ i o d i d e ~} 5$. 
The first step in this chain cycloaddition reaction is production of a tri-n-butyltin radical, and in subsequent reaction with alkenyl halides 5 homoallyl radical 2 is generated. Although the homoallyl radical 2 may be in an equilibrium with cyclopropylmethyl radical ${ }^{16}$, intermolecular conjugated addition onto the eleciron-deficient olefinic bond $\underline{l}$ is predominant reaction when olefinic compounds were used in an excess (Scheme 3.). Only minor amount of buten derivatives (e.g. 5 , $X=H$ ) as a reduction products (up to $8 \%$ ), were detected. This C-C bond forming reaction generates an adduct radical $\underline{3}$ which is much less nucleophilic because of the presence of nitrile or other electron-withdrawing group. Possessing an appropriate

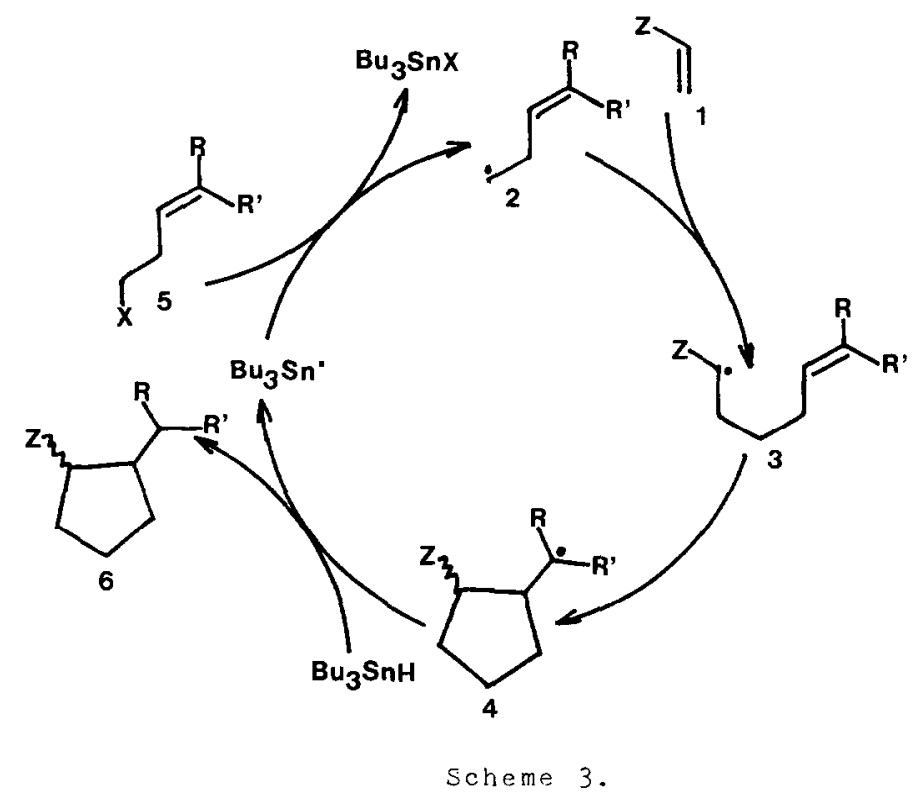

located olefinic bond (e.g. i $\delta$-position) radical 3 rather undergoes to the 5 -exotrigonal intramolecular addition to close a cyclonentane ring 4 than to the $\underline{5-e n d o-}$ cyclization or hydrogen abstraction from organotin hydride, since cyclohexane derivative or unsaturated nitrile have not been detected in the reaction mixtures. The fate of cyclopontylmethyl radical Il generated after ring closure reaction, i.e. second $C-C$ bond formation, depends of the substituents on the radical centre and reaction conditions. More stable tertiāry radicals $\underline{4}\left(R=R^{*}=P h\right.$ and $R=P h$, $R^{*}=M e$, Expts. $i$ - v) rather undergoe to abstraction of hydrogen from tin hydride thus affording a saturated cyclopentane derivatives 6 than to addition reactions. However, when tertiary radicals are not benzylic, e.g. 4 ( $R=R^{`}=$ Me, Expts. vi - ix) or is primary racical, e. $g .4\left(R=K^{*}=H\right.$, Exp. $\left.x\right)$ they rather undergo to the intermolecular addition onto the olefinic compounds 1 thus producing a new $\alpha-s u b s t i t u t e d$ radical 8 (Scheme 4. Table 1.). Termination reaction for such a radical is nydrogen abstraction thus giving a difuctional cyclopentane derivative of type 7 as a rinal producls of the tiree c-c bond formation proces ${ }^{17}$.

The other possibilities of free radical two steps cyclopentane ring annulation are in progres. 

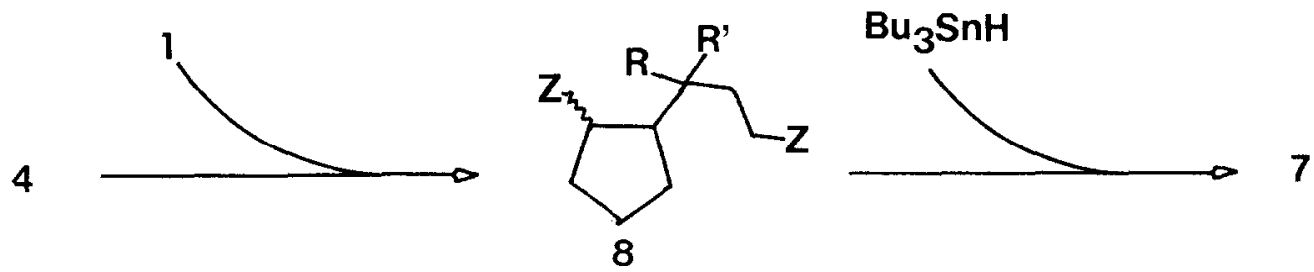

Scheme 4 .

\section{References}

1. B. Giese, Angew. Chem. Internat. Ed., 22 , 753 (1983); B. Giese. Augow. Chem. Inter nat. Ed. , 24 $, 553,1985$ ) and references therein; R. Henning and H. Urbach, Tetrahedron Letters, 24, 5343 (1983); B. Giese and H. Holer, Tetrahedron, 31, 4025 (1985

2. C. Walling, J. H. Cool\%, A. R. Ponars and E. J. Racah, J. Am. Chem. Soc., 88, 5361 (1966); C. Walling and A. Ciofrari, J. Am. Chem. Soc., 94, 6064 (1972).

3. A. L. J. Reckujth and K. Ingold, free Radical Rearrangement, in Rearrangement in Ground and Excited States, Vol. I. Academic Press Ino, New York, 1980; A. L. J. Beckwith and C. H. Schiesser, Tetrahedron, 41,3925 (1985).

4. A. L. J. Becksith, Tetrahedron, 37, 3073 (1981); S. - U. Park, S. -K. Chung and M. Newcomh, J. 4m. Chem. Soc., 103, $240(1986)$.

5. J. -M. Surzur in Reactive Intermediates, Ed. by A. A. Abramovich, Vol. 2. Ch. 3, Plenum Press, lew York, 1981 .

D. D. H. R. Barton, private communication; E. I. Corey and S. G. Pyne, Tetrahenron Letters, 24, 2821 (1933); D. Belotti; J. Cossy, J. P. Pete and C. Portel. Ia, Tetrahedron Lettorg, 26, 49.4 (2905); N. N. Marinoví́ and H. Ramanathro. Tetrahedron Letecrs, 24, 197 : $(1383)$.

7. D. P. Curran and D. Y. Rakiewicz, Tetrahedron 4l, 3943 (1985).

8. J. W. Wilt, tetrahedron, 4 l, 3979 (1985).

9. G. Stork, R. Mook, S. A. Biller and S. D. Rychnovsky, J- em. Chem. Soc., 105, 3741 (1983); Y. veno, K. Cnino, M. Okawa, Tetrahedron Letters, 23, 2575 (1982).

10. J. -K. Choi and D. J. Hart, Tetrahedron, 41, 3959(1985).

11. G. Pattenden and G. M. Robertson, Ietrahedron, 41, 4001 (1985).

12. G. Stork and P. M. Sher, J.Am. Chem. Soc., 108, 303(1986).

13. A. C. Angoh and D. L. J. Clive, J. Chem. Soc., Chem. Commun., 980 (1985'.

14 Tri-n-butyltin halides were separated from the reaction mixture by washing of an etheral solution of reaction products with $10 \%$ aqueous potassium fluoride. precipitated organotin fluoride was filtered off and organic layer worked up on the usual manner. J. E. Leibner and J. Jacobus, J. Org. Chem., 44, 449 (1979).

15. R. Giese and J. Dupuis, Angew, Chem. Internat. Ed., 22, 622 (1983).

16. D. Griller and K. "I. Ingold, Acc. Chem. Res., 13, 317 (1980).

17. Radical $\underline{8}\left(K=R^{*}=H\right)$ undergoes to further addition reaction onto $\underline{1}$ and several telomaric compounds were detected.

(Received in UK 10 October 1986) 